\title{
E-Learning Innovation: Factors Affecting the Pedagogical Journey at Bendigo Kangan Institute
}

\author{
Usman Durrani ${ }^{*}{ }^{*}$, Zijad Pita ${ }^{2}$ \\ 1 Bendigo Kangan Institute, Melbourne, Australia. \\ 2 Holmes Institute, Melbourne, Australia. \\ * Corresponding author. Tel.: +61 450220338; email: dr.udurrani@gmail.com \\ Manuscript submitted September 15, 2016; accepted October 27, 2016. \\ doi: 10.17706/ijeeee.2016.6.4.208-219
}

\begin{abstract}
Effective planning and implementation of innovative e-learning solutions requires deep understanding of the factors which drive innovation. These drivers include strategy, senior leadership, business case, resourcing, champions, people support, and technological support. In addition, a good understanding of organisational capabilities, practices and their e-learning strategies also facilitate in driving sustainable e-learning innovation. In contrast, the role of disruptive innovation is equally important, as it presents established organisations with access to new markets and longer-term strategic directions to sustain existing businesses. At present, there is little evidence on how educational institutions are planning for such innovations. This paper explores the influence of these factors in driving both sustainable and disruptive e-learning innovations within the Australian Tertiary And Further Education (TAFE) sector. In particular, it will study Bendigo Kangan Institute (BKI) TAFE with the aim to employ the innovation factors to analyse sustainable and/or disruptive innovations.
\end{abstract}

Key words: Disruptive, e-learning, innovation, sustainable.

\section{Introduction}

Innovation is a process which starts with an initial decision of adoption, diffusion, implementation and integration of core practices [1]. From the perspective of sustainable e-learning, innovation is about embedding new concepts and technology for education and training, but with the emphasis to have stable delivery processes and structures which can be integrated institutionally [2].

Effective planning for a sustainable e-learning innovation requires deeper understanding of factors which drives innovation. These factors include strategy, senior leadership, business case, resourcing, champions, people support, and technological support [2]. In addition to these factors, sustainable e-learning innovation also requires good understanding of current teaching and learning models, practices and their associated e-learning strategies.

In contrast, disruptive innovation emphasizes bringing new products (not necessarily better products) to existing customers with ability to "disrupt" an existing market. For established organisations, it is important to understand the process of disruptive innovation, as it offers access to new markets, and longer-term strategic direction to sustain existing businesses [3].

A number of sustainable e-learning innovation models have emerged to address the concerns of the learner along with the challenges and capabilities of present pedagogical technology for effective online and blended delivery [1], [4]-[6]. However, at present there is little evidence about how Technical and Further 
Education (TAFE) institutes are effectively planning their sustainable and/or disruptive e-learning innovation [5].

This paper explores the influence of these innovation factors in driving the sustainable or disruptive e-learning innovation within Australian TAFE sector. It will particularly study Bendigo Kangan Institute (BKI) - a leading Victorian TAFE institute in Australia and its current teaching and learning models in campuses. The aim of this paper is to employ the innovation factors in a diagnostic tool to analyse sustainable and disruptive innovations in the BKI workplace environment and to discuss how it has enabled the institute to be entrepreneurial and increase productivity through metropolitan, regional, national and international training delivery.

\section{Literature Review}

\subsection{Sustainable vs. Disruptive Innovation}

Literature on innovation reveals two main types of innovation that may affect institutes, organisations, and businesses both in sustainable and/or disruptive manners [7]. Disruptive innovation represents innovation that delivers a physical product or a service to consumers in a way which goes against market expectations [3]. In other words, the purpose of disruptive innovation is to attempt to bring simpler, more convenient and less expensive products or services to established customers in existing markets [7].

By contrast, sustainable innovation focusses on high-end users who demand better performance of an existing product or service and are willing to pay more for it [3]. This performance improvement can be incremental or of a breakthrough nature [7].

It is important to point out, that technology can be applied to both sustainable and disruptive innovation. But from an education delivery perspective, disruptive innovation requires more an autonomous learning program which is not affected by the host institute's culture, processes, systems and decision making mechanisms [3].

Leading educational institutes often focus on sustainable innovation in order to meet the needs of their high-end customers. This leaves new entrants to use disruptive innovation to explore new horizons. For leading educational institutes, it is important to understand the process of disruptive innovation as it provides access to significant new markets, new ways to be sustainable and contributes to the long term survival of established businesses [3].

Sustainable e-learning innovation as a product, system or service is defined as: 1) being developed and implemented by one or more educational institutes; 2) passing a proof of concept stage and being judged, on the basis of evidence, as beneficial for teaching and learning; 3) having produced evidence of potential to be adopted, and possibly adapted, for use beyond the original development environment; and 4) it supports a model where maintenance, use and further development are not dependent on the one or few individuals who created it, to the extent that, if their involvement ceased, further prospects would be compromised [8].

Past studies on sustainable e-learning innovation had identified a number of themes which question the value of innovation for an institute, in teaching and learning, and in the institute's structural aspects, policies, processes, and procedural changes [2], [8]. These studies have indicated that a product or service only becomes sustainable where innovators took the step backwards to 'handover' it to the institute, a use community or other contributors [8].

For the purpose of this research, sustainable and/or disruptive e-learning innovation will be investigated in the context of BKI's campuses using the seven driving critical factors.

\subsection{Critical Success Factors for e-Learning Innovation}

E-learning innovation is about embedding new concepts and technology for education and training, but 
with the emphasis on having stable delivery processes and structures which can be integrated institutionally [2]. A review of the literature reveals that e-learning innovation requires an integrated, strategic approach across all areas of organisations with innovation as its core value.

In order for an organisation to be truly innovative, it requires the continuous reassessment and evaluation of its culture, systems and procedures. Teams and well trained staff are the crucial element in the sustainable innovation process [5].

As argued by [9], critical success factors for e-learning innovation include knowledge management, a learning architecture, the organisation's technology, a learning culture, and a sound business case. These factors can institutionalise learning through the use of technology and bridge learning with business goals [5].

The RIPPLES model was introduced by [1] comprising of seven critical success factors to institutionalise e-learning innovation. It includes: resources, infrastructure, people, policies, learning, evaluation, and support. It was also highlighted that misalignment of any one of these factors could impede the continued progress of e-learning innovation. Based on [1] framework, [10] developed a seven factors business model for innovation. The factors included in this model were strategy, senior leadership, business case, resourcing, champions, people supports, and technology.

In addition to the critical driving factors stated above, any sustainable implementation of e-learning in a workplace environment basically requires three fundamental building blocks [11]. These building blocks include a strategic plan, organisational elements, such as, leadership, change management strategies, and technology infrastructure. The last building block includes e-learning program elements, such as, instructional system, roles and competencies of staff, and technology infrastructure.

More recently, studies were performed to examine conditions associated with the continuation of e-learning initiatives within educational institutes [12], [13]. According to [12], four factors that ensure the integration and sustainable development of e-learning in education organisations include: collaborative working practices, leadership, user friendly technology, and support. As per this study, collaboration is considered as a key challenge where teachers have to deliver their full teaching work load along with disruptive adoption of new technological tools and concepts as directed by the institute's visionary leadership.

In their study on sustainable innovation [13] categorised 23 different factors associated with continuance (sustainability) of e-learning initiatives into five sets based on the structural division of roles in various educational institutions. These sets of factors include institutional factors, developer factors, teacher factors, student factors, and technology factors. It was concluded, that merely having an e-learning initiative that works for students and teachers is not enough for sustainability. Sustainability of learning initiative depends heavily on various institutional factors such as, financial support, formal recognition of developer activities and up to date but sufficiently mature technology [13].

For the purpose of this study, we will adopt the [10] business model and will use it as a diagnostic tool to identify the role of seven factors in driving innovation around e-learning in BKI campuses. We believe this selection is feasible for our research study because of its prior usage in context of studies conducted at various Australian TAFE sector and RTOs [2].

\section{Research Methodology}

\subsection{Research Questions and Conceptual Framework}

This study will investigate following two research questions. 1) What is the evidence of sustainable or disruptive e-learning innovation at Bendigo Kangan Institute? 2) What factors supported Bendigo Kangan Institute in achieving this e-learning innovation? 
Fig. 1 illustrates the conceptual research framework used for this study. As shown in Fig. 1, seven critical factors of e-learning innovation along with two innovation lenses were identified to investigate the case study in BKI environment.

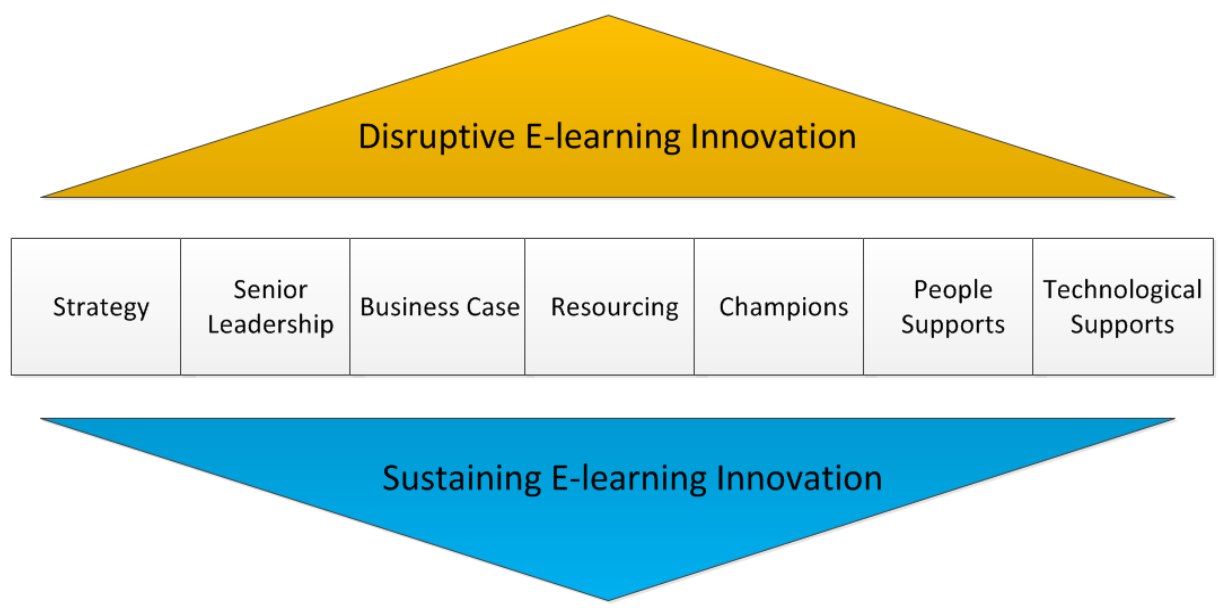

Fig. 1. Conceptual research framework.

The 'strategy' represents a vision, values, and planning that underpins e-learning as a core feature of the current and future operations at BKI. The 'senior leadership' should provide the support to e-learning champions and promote the use of e-learning tools through cultural and structural changes. In addition to support from senior leadership, a strong and continued business focus or 'business case' can bring benefits through flexible training to a dispersed workforce, in a consistent and high quality manner.

A strong business case and the support of senior leadership can promote e-learning innovation through better 'resourcing' for initial and subsequent efforts across any organisation or institution. E-learning cannot succeed without the existence of e-learning 'champions'. These champions can contribute to innovation through their expertise in instructional design and by implementing new technologies for online and blended delivery.

Support from various stakeholders 'people support', such as, IT, teaching, and administration staff who share the vision and strategic goals of promoting e-learning solutions, is equally important for sustainable and/or disruptive innovation. The last critical factor for successful e-learning innovation relies on the presence of reliable and robust network facilities or 'technological supports'.

This study will investigate these critical factors (as illustrated in Fig. 1) and their relation to disruptive and/or sustainable e-learning innovation in the context of a BKI case study. It will use a disruptive e-learning innovation lens to identify (if any) physical products or services to BKI consumers go against market expectations [3]. It will also use a sustainable e-learning innovation lens to understand if the performance of any existing BKI product or service was enhanced for high-end BKI users and whether these high-end BKI users were prepared to pay more for this enhancement [3].

\subsection{Research Methods}

The two research methods used for this study include a structured literature review through selected peered-reviewed journals and international conference proceedings on e-learning innovation critical success factors and different e-learning initiatives, and the examination of a Bendigo Kangan Institute (BKI) case study and its pedagogical journey.

Fig. 2 illustrates the research model for this study.

For this study, highly ranked international peer-reviewed journals that publish reflective descriptions and 
evaluations of local e-learning innovations were selected, for example, the 'Journal of Computer Assisted Learning and Computers \& Education'. In addition to peer-reviewed journal papers, leading international e-learning conference publications were also referred to, such as, 'EdMedia: Work conference on educational multimedia, hypermedia and telecommunications'. Through these published resources, e-learning innovation critical success factors were identified for further use in the BKI case study.

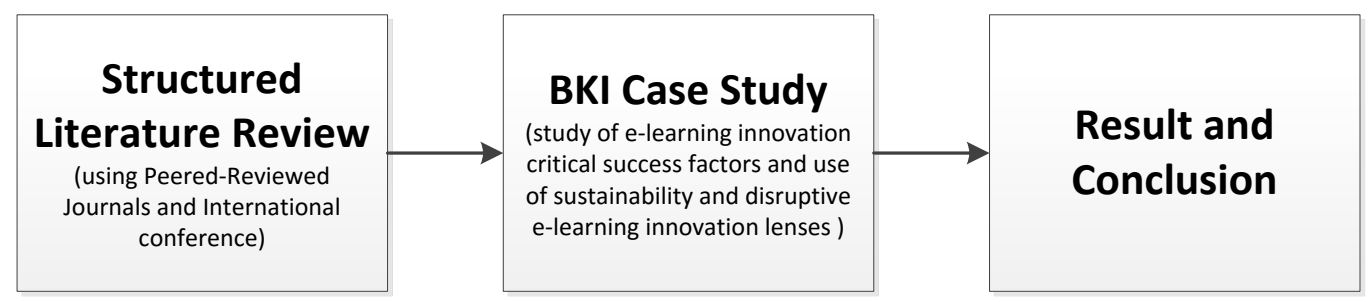

Fig. 2. Research method.

These papers were selected purposefully, so that they emphasise contributions to practices. Papers from conference proceedings were included to capture initiatives that might be current in the innovation area as well as those that were published in the formal journal literature, as the latter are subject to longer review times and encourage complete work rather than work in progress. The selection criteria for this study were adopted from [13].

Selected papers potentially 1) improve the learning and teaching outcomes and/or, 2) improve the quality or ease of assessment and/or, 3) enable more flexible delivery and/or, 4) increase the student engagement or satisfaction.

A total of 45 papers were identified that met the criteria. Based on this selection, information about various e-learning initiatives that met the criteria for inclusion in the study was obtained from the papers that described it.

After the structured literature review, in the second phase, a qualitative approach was adopted through a case study as it was considered reasonable and also appropriate to understand the phenomenon through the examination of people's behaviour and perspectives and the context in which phenomenon occur [14].

In any qualitative study, 'context' is considered as a crucial element. Within this research, the case study was conducted in a routine natural setting through qualitative tools such as, interviews, observations, and the investigation of archival records to systematically analyse the data using techniques such as, content analysis [15], [16].

All research data was collected through interviews with 32 BKI management, administrative and teaching staff members. These staff members were selected from different departments, namely, business, IT, fashion, hospitality and engineering, with ages ranging from 25 to 60 years old. This data was collected within the period of six months (July 2015 to Jan 2016) and within that period on-site observations also took place. In order to conduct these interviews proper ethics approval was sought. In addition to interview and observations, organisational documents were retrieved and field notes were also taken. All informal channels of communications were not considered for additional data gathering, such as, emails, online chats, and casual offline discussions.

This study employed the thematic analysis as suggested by [17] as the primary data analysis technique. This data analysis technique provides descriptive presentation of qualitative data that includes a system of themes based on iterative reading and coding of speech units, points of interest, and concepts [15]. Using the seven critical factors along with two e-learning innovation lenses (as illustrated in Fig. 1) data was analysed and then mapped with different critical factors and e-learning innovation lenses. To help in this process NVIVO was used for word frequency tabulation and word cloud generation. 


\section{Bendigo Kangan Institute (BKI) Case Study}

BKI with its history stemming back to 1925 has more than 80 years of experience in vocational education and training. BKI programs are delivered in 10 Victorian campuses, along with various workplaces, and in many other education, government and corporate locations as well as online.

With more than 40,000 enrolments a year, BKI is considered as a major Victorian TAFE institute for the automotive, health and nursing sectors and indigenous education. It also has a strong presence in a range of industries such as fashion, business, IT as well as justice and legal.

Although BKI has undertaken various e-learning initiatives since 2005, in 2015, BKI launched its enterprise level strategic vision of 'BKI2020'. The key purpose of the vision was to '...empower people and industry with the skills to create a bright future...' with the aim to '... help 100,000 people take the next step in their careers and to help industry plan and build the workforce of the future'. In order to establish this alignment between strategic vision and existing practices, various business and technological shifts were identified. These shifts were not only linked with customer needs, market dynamics, and technology impact, but also will likely to impact the BKI business model.

\subsection{Strategy}

Since 2005, BKI has adopted a number of e-learning initiatives at different individual or departmental levels, where an e-learning platform through Moodle was established and various learning and delivery technologies, such as, Camtasia, use of videos from Youtube, and the Big Blue Button were incorporated. However, the institute took its first enterprise level e-learning initiative in 2015 by launching their strategic vision of 'BKI2020'.

The ten shifts which underpinned BKI vision and its associated strategy included: 1) From one customer to two, 2) From jobs to pathways, 3) From student-led to industry-led, 4) From teaching to engaging, 5) From steady to disruptive, 6) From diverse standards to a consistent experience, 7) From transactions to relationships, 8) From TAFE-centric to a group of specialist business units united by common goals, 9) From Victoria to Australia to International, and 10) From actions to outcomes.

Out of the above ten shifts, the three shifts directly relevant to BKI e-learning initiatives include: First, from 'teaching to engaging' - which describes the demand to provide teaching practices that suit the increasingly diverse need of students (especially in regional areas) and industry partners. This shift has not only impacted course content but it has influenced the way the Institute delivers, teaches and supports students (e.g. learning for life and flipped learning). Second, from 'steady to disruptive' - which highlights the embrace of technology and change while becoming adaptable and agile in the way Institute operates. Third, from 'diverse standards to a consistent experience' - which promotes the need for all BKI teaching departments to have a consistent mechanism to deliver their courses through the use of enterprise level learning management systems and associated tools and technologies.

\subsection{Senior Leadership}

Based on the strategic vision of 'BKI2020' a number of road shows across all BKI campuses were organised in 2015 by the Institute leadership who actively participated by presenting their vision for the next five years. In the words of BKI's CEO:

‘...One of the biggest issues hampering organisations all over the world is a lack of understanding. Employees simply don't understand their employer's strategy, vision and goals, because leaders haven't been clear about them...This hampers their ability to make decisions and work together...I want to change this, because the benefit of giving you a clearer picture of our future is enormous...'

Using different data collection techniques, BKI senior management collected 700 responses across the 
institute and categorised these 700 ideas into key themes for input into the development of BKI's strategic vision (2015-2020).

'...The world we now operate in is changing at a rapid pace...This is a challenge, but also a great opportunity, if we embrace technology and change while becoming adaptable and agile in the way we operate. Over the next five years, we will see e-learning, Massive Open Online Courses (MOOCs) and virtual classrooms become truly prominent, while emerging manufacturing technologies, such as 3D printing...'

\subsection{Business Case}

BKI with its ten Victorian campuses and seven portfolios, such as, commercial, organisational development, business assurance \& performance, learner experience, learning innovation, learning areas, and centres of excellence has been involved with various state and national e-learning initiatives from 2005. These initiatives include, but are not limited to the following: 1) Availability of technology-based professional development training with collaborative partnerships. 2) Research made available into the national 'E Learning for Industry' and 'New Practices in Flexible Learning' Projects. 3) Exploration and utilisation of a Learning Management System - 'MyLearning'. 4) Customization of TAFE courseware and leading supplier of the nationally funded 'Flexible Learning Toolboxes'. 5) Participation in national and state 'E-Learning Networks. 6) Alignment with other funding opportunities, i.e. E-Learning Innovation etc.

There were several factors which contributed to BKI's decision to move towards embedding and sustaining its use of e-learning for delivery of their qualifications: 1) Cost efficiencies to deliver courses online/blended as compared with traditional face-to-face methods in the regional context. 2) Equity of access across metropolitan and regional workspaces. 3) Ability to address the difficulty in getting employee engagement to participate in continuous and regular training. 4) Provision of a contemporary and engaging professional development platform for the BKI staff to maximise their potential.

In support of online education delivery, one of the managers stated:

'...There is a need to support employees in the workplace who wish to undertake study at a time and place of their choosing. At this juncture many employees of organisations who have been in Industry a number of years and wish to now pursue a qualification to enhance their years of work experience are precluded from study due to the time constraints placed on their lives...This will provide enormous opportunity to many employees to undertake some form of study utilising online communication tools...Teachers will also benefit by gaining skills in more advanced technology...to integrate their resources in an environment to facilitate sharing ...'

\subsection{Resourcing}

Since 2005, various e-learning grants were received by the Institute through successive Victorian governments and industry or education partners. Examples include, the Office of Training \& Tertiary Education (OTTE), the TAFE Development Centre (government organisations) while the most recent example of an education partnership is through Federation University (2015-2016) which provided a grant to run a teacher professional development initiative 'Epigeum - Teaching Online Program'.

This funding supported the Institute's innovative projects most often targeted at teaching departments. These funding sources have greatly assisted BKI to build its well-recognised capability around e-learning. These grants were given to primarily support key performance indicators: 1) Capability for e-business increased. 2) Workforce capacity to be flexible, innovative leaders responsive to customer needs. 3) Capability for e-Learning and on-line assessment increased. 4) Evidenced-based decision making drives program offerings and delivery models. 5) Minimising bureaucratic barriers, to become a truly learner centred Institute.

Internal resourcing to support e-learning is also recognised as a key factor in embedding innovation. The BKI Health and Community Centre of Excellence (HACCOE) in partnership with the BKI Product 
development \& Management team has recently established a dedicated team of instructional designers to support the centre in embedding e-learning technologies and practice in recognition that nursing, allied health, aged care and community services are high demand occupations and an expanding industry market.

\subsection{Champion}

BKI institute with its two specialised teams 1) My Learning Support and 2) Product Development \& Management are providing their services to establish an e-learning framework and to support all teaching departments in delivering their qualifications through online and blended delivery models. Members of these teams champion e-learning ideas, frameworks and models to facilitate effective online teaching and learning methodologies.

A team facilitated approach has been taken to embed and sustain leading edge e-learning and to deliberately avoid developing individual e-learning champions. These teams work to provide consistent and comprehensive support to the take up e-learning across all BKI teaching departments. For example, the Product Development \& Management team works as 'education solutions partners' with teaching department to embed e-learning. Initiatives include participatory or co-design of blended and online courses to promote teacher engagement with innovation.

The BKI Food and Fibre Centre worked closely with their partner to embed flipped learning across a range of teaching areas including Food and Fibre (Animals, Plants and Sciences) Animal Studies and Agriculture courses including organics. The Centre is currently developing online learning content and assessments - knowledge and practical elements both at BKI (simulated) with the majority of these courses using the Flipped Leaning model will be available locally, nationally and internationally.

\subsection{People Supports}

Aligning with the BKI2020 strategic vision to refocus from 'teaching to learning' and from 'steady to disruptive', Epigeum - teaching online professional development program was organised at BKI to assist teaching staff to develop their ability to design and deliver high quality online and blended courses in their area of specialisation.

Twenty five teachers from different departments were nominated by the management to attend a 14 week intensive online course comprising of various competency based assessment activities, such as, online quizzes, assignments, and mandatory discussion forums. In addition to this, seven virtual classroom sessions were also delivered using Adobe Connect meeting to discuss various teaching and pedagogical concepts and to share participants' experiences in context.

Along with the assessment activities, seven virtual classroom sessions were also delivered (as illustrated in Fig. 3). As part of the plan, the facilitator engaged pre-selected participants and assigned them the responsibilities to deliver one of the virtual class rooms through Adobe Connect meeting.

As stated by one of the participants' in a program feedback survey:

'...The best part of the course was listening to others who have already been working in the online sphere and sharing with them...The time frame was not suitable. It was advertised as 3 hours per week over 14 weeks (42 hours) but if you were doing it properly, reading all the information, doing the portfolio tasks, responding to forum questions, doing the quiz and assignments, the time spent was at least double this...'

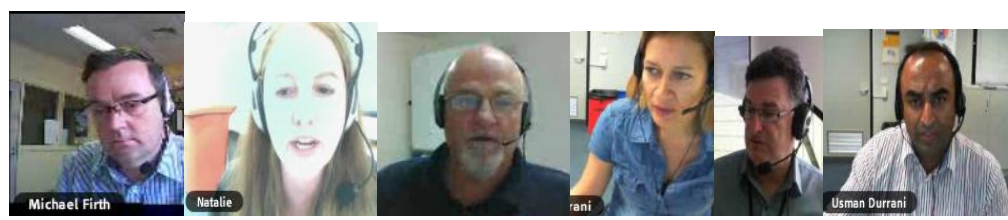

Fig. 3. Epigeum participants during their virtual. 


\subsection{Technological Supports}

In order to support BKI's technological needs for e-learning delivery and operations, the Institute uses 'eWorks' which is an independent BKI business unit and one of Australia's leading vocational education and training e-learning delivery and consultancy specialists. eWorks provides a wide range of products and services that support BKI to maximise the benefits of online education. A recent initiative has been the development of the ASMS technology- based platform which develops and manages apprentice learning plans in the BKI Automotive Centre of Excellence (ACE). Apprentices work through theoretical and practical sessions at their own pace and in the order that best fits their employer and personal needs. This model has proven so successful that ACE has expanded training delivery through national partners and has plans for international delivery.

In addition to support provided by eWorks for the stable Moodle learning management system, BKI's well-equipped IT department also provides additional support for a reliable network environment.

Individual teaching staff makes use of webinar tools, social networking spaces, and wireless technologies to support teaching and learning. One such example is the use of an 'Online Observation checklist' in Moodle to assess practical work in class and the workplace using iPads and iPhones. The checklist integrates back into the Moodle Gradebook which makes efficient use of assessor's time. Concepts of gamification tools as promoted in different professional development units are gradually picking up pace.

\section{Conclusion and Discussion}

In this section, the findings are discussed from the BKI case study and the following questions are addressed as highlighted in the research methodology section of this paper:

- What is the evidence of sustainable or disruptive e-learning innovation at Bendigo Kangan Institute (BKI)?

As discussed in the previous sections of this paper, disruptive innovation represents innovation that delivers a physical product or a service to consumers in a way which goes against market expectation. Whereas, sustainable innovation focusses on high-end users who demand better performance of an existing product or service and are willing to pay more for it.

Within BKI, the introduction of an enterprise level e-learning strategy and the vision of 'BKI2020' have produced a disruption across the Institute which has resulted in management seeing an increase in consistent e-learning best practice and technology use in all teaching departments. A key emphasis is to adopt technology-based systems and technologies to move from teaching to engaging with students during delivery and to introduce different delivery concepts, such as flipped learning to provide an engaging, practical and 'real world' learning experience for students. This initiative has also enabled the institute to be entrepreneurial and expand productivity through online training delivery.

The presence of BKI executives and senior management during campuses roadshows and their active participation in presenting and promoting various e-learning concepts and systems promoted the innovation which was not considered as a common norm within the Institute culture. Opportunities to question senior leadership in open discussion forums helped in the implementation of e-learning systems and encouraged teachers and operational staff in the adoption of technology.

The BKI2020 strategic vision, support of senior leadership and the strong business case facilitated in various e-learning professional development initiatives such as the Epigeum - teaching online program in addition to the utilization of MyLearning (Moodle) for program delivery, development and customization of courseware. The presence of e-learning champion teams to support and facilitate the delivery of online and blended learning courses for the teaching departments has also changed the norms and the way e-learning was previously delivered by the teaching departments.

Based on the discussion above, it is evident that both sustainable and disruptive e-learning innovation 
was applied at different stages by the institute. Disruption innovation was mainly used to redirect the institute's strategy and vision for the coming five years. Whereas, sustainable innovation was mainly applied to meet the demand of high-end users by providing better performance of the tools and technologies previously disrupted institute's norms.

- What factors supported Bendigo Kangan Institute (BKI) in achieving this e-learning innovation?

Table 1 provides seven factors along with its mapping with different types of innovation as identified in BKI environment (between July 2015 to Jan 2016).

Table 1. CSF Supported BKI in Achieving e-Learning Innovation

\begin{tabular}{ccc} 
CSF for e-Learning Innovation & Sustainable Innovation & Disruptive Innovation \\
\hline Strategy & $\checkmark$ & $\checkmark$ \\
Senior Leadership & $\checkmark$ & $\checkmark$ \\
Business Case & $\checkmark$ & $\checkmark$ \\
Resourcing & - & $\checkmark$ \\
Champions & $\checkmark$ & $\checkmark$ \\
People Supports & - & $\checkmark$ \\
Technological Supports & $\checkmark$ & $\checkmark$
\end{tabular}

As it can be observed from Table 1, in the context of this BKI case study, disruptive innovation was ticked against all seven critical success factors. However, sustainable innovation was evident in all except two factors; 'resourcing' and 'people support'. Few reasons for this are as follows: 1) Due to government funding cuts many training programs were discontinued and some learning projects became unfeasible to sustain. 2) Teaching and operational staff had initially shown their interest in participating in various e-learning programs and workshops, but due to their extra work commitments and lack of backup support, many of the participants weren't able to keep up with the pace of e-learning professional development activities.

This analysis was based on a data collected between Jul 2015 to Jan 2016. Comparing it with the present state of e-learning innovation in BKI, we can state that it is rapidly evolving as a result of internal continuous improvement efforts across the institute. For example, the BKI Health and Community Centre of Excellence (HACCOE) in partnership with the BKI Product development \& Management team has recently funded and established a dedicated team of instructional designers to support the centre in embedding e-learning technologies and practice in nursing, allied health, aged care and community services.

Similarly, based on the above analysis a number of improvement opportunities were identified to enhance 'People Support'. For Example, in a more recent project, BKI Food and Fibre Centre in collaboration with e-learning champion teams worked closely with their business partner to embed flipped learning within their online/blended delivery models. In addition, the institute is planning and organising a series of professional development workshops to educate BKI teaching departments on e-learning pedagogy and its values through online and blended delivery models.

The role of sustainable and disruptive innovation has embedded the use of e-learning technologies and enabled the institute to expand training delivery across metropolitan and regional campuses with key initiatives being ACE delivery of automotive apprenticeships nationally, online delivery of Food and Fibre Centre courses and the new HACCOE instructional design team. This has resulted in tangible productivity gains for the institute.

\section{Implication and Limitations}


This study has a limitation to generalisation because it has only used a single case for a research method. Although, before executing this case study, structured literatures review of selected 45 papers with relevant cases for reference has been performed, still this paper has room for improvement by following studies.

In addition, this study was conducted, only focusing on official channels for data gathering including interviews, structured environment observation, and documentation review, excluding all unofficial types of communication including emails, messenger chats, and offline casual meetings.

Therefore, as a suggestion to the following studies, these unofficial channels should be included, in addition to the use of integrated quantitative research methods, such as, questionnaire survey and usage survey in designing a research.

\section{References}

[1] Jasinski, M. (2007). Innovate and Integrate: Embedding Innovative Practices. Australian Government: Department of Education, Science, and Training.

[2] Callan, V. J., \& Bowman, K. (2010). Sustaining e-Learning Innovations: Vignettes on 10 Funded Organisations.

[3] Yuan, L., \& Powell, S. (2013). MOOCs and disruptive innovation: Implications for higher education. E-Learning Papers, 33(2), 1-7.

[4] Australian National Training Authority. (2002). Six Degrees of Innovation: A Practical Guide for Building an Innovative Organisation, Innovation: Ideas That Work.

[5] Callan, V. J., \& Bowman, K. (2010). Sustaining e-Learning Innovations: Literature Review.

[6] Engelbrecht, E. (2003). A Look at e-Learning Models: Investigating Their Value for Developing an e-Learning Strategy.

[7] Christensen, C., \& Raynor, M. (2013). The Innovator's Solution: Creating and Sustaining Successful Growth. Harvard Business Review Press.

[8] Gunn, C., \& Herrick, R. (2012). Sustaining eLearning Innovations: A Research Study Report. Centre for Academic Development, University of Auckland.

[9] Rosenberg, M. J. (2001). E-Learning: Strategies for Delivering Knowledge in the Digital Age. New York: McGraw-Hill.

[10] Callan, V. J., \& Bowman, K. (2011). Sustaining e-Learning Innovations: A Review of the Evidence and Future Directions.

[11] Berge, Z. L., \& Giles, L. (2008). Implementing and sustaining e-learning in the workplace. International Journal of Web - Based Learning and Teaching Technologies, 3(3), 44-53.

[12] Didiot-Cook, H. (2013). From enthusiasm to strategy: Four critical factors to sustain the development of technology enhanced learning in educational organisations. Proceedings of 6th International LINC Conference MIT. Cambridge, Massachusetts, USA.

[13] Tanya, J., McGill., J., Klobas, E., \& Stefano, R. (2014). Critical success factors for the continuation of e-learning initiatives, The Internet and Higher Education.

[14] Kaplan, B., \& Maxwell, J. (2005). Qualitative research methods for evaluating computer information systems. Evaluating the Organisational Impact of Healthcase Information Systems, pp. 30-55. Springer New York.

[15] Anderson, R. (2007). Thematic Content Analysis (TCA). Descriptive Presentation of Qualitative Data.

[16] Creswell, J. W. (2007). Qualitative Inquiry \& Research Design: Choosing among Five Approaches (2nd ed.). Thousand Oaks: Thoudsand Oaks: Sage Publication.

[17] Braun, V., \& Clarke, V. (2006). Using thematic analysis in psychology. Qualitative Research in Phycology, $3(2), 77-101$. 


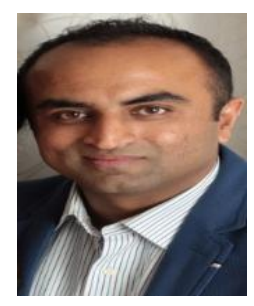

Usman Durrani received his PhD in information systems in 2014 and a masters of applied sciences (IT) in 2004 from RMIT University Australia. As a certified ITIL v3 (2012) and certified Project Management Professional (PMP), Dr. Durrani has managed numerous industrial and research projects with a combined total experience of 15 years. In addition to his industry experience, he also held various academic positions in various international educational institutes in South Asia, Middle East and Australia.

At present, Dr. Durrani holds a senior educator and e-learning specialist position at Bendigo Kangan Institute Melbourne Australia with the key responsibility of delivering IS and IT courses and to develop and manage e-learning platform. As an active researcher, he has presented in several international conferences on software engineering and information technology and also published in many top ranking international research journals. His research interest includes adaptable management systems, application of lean thinking, e-learning and innovation.

Zijad Pita received his PhD and master's degree from RMIT University in Australia. He was awarded the most outstanding academic performance in the Master of Business in Information Technology and PhD at RMIT University 2000 and 2007. He has held numerous positions at RMIT University and in various industries. Currently he is Program Director of Information Systems and Head of Learning and Teaching at Holmes Institute. He has presented papers at national and international conferences in Europe and Australia. His research is in the Strategic Information Systems area and due to be published book Strategic Information Management. His research interests include strategic information systems planning, business modeling and simulation of complex systems, decision support systems and knowledge management. 